\title{
Clinical Profile of Early Diagnosed Dengue Fever in Hospitalized Children in South Delhi
}

\author{
Preeti Sharma • Chandra Mohan Kumar • A. K. Patwari
}

Received: 10 September 2013 / Accepted: 20 February 2014 / Published online: 16 March 2014

(C) Dr. K C Chaudhuri Foundation 2014

To the Editor: Dengue fever (DF), an acute febrile illness caused by dengue viruses belonging to the family Flaviviridae, remains a major cause of morbidity and mortality among children in South East Asia [1]. Since the clinical presentation and severity of dengue infection has been changing with every outbreak, we aimed to study the clinical and laboratory parameters of children admitted with dengue fever during the latest outbreak.

In this prospective study conducted in a multi-speciality teaching hospital in Delhi, hospitalized children testing positive for NS1 antigen were enrolled. Cases were classified into three groups: Dengue (D), Dengue with warning signs (DW) and Severe Dengue (SD), according to WHO Classification [2].

Among 60 patients of dengue fever $11.7 \%$ were classified as D, $83.3 \%$ as DW and $5 \%$ as SD group. Seventy-eight percent had thrombocytopenia and $15 \%$ had total platelet count (TPC) below 50,000. All the nine cases with platelet count $\leq 50,000 / \mathrm{cu} \mathrm{mm}$ had leucopenia, and $33.3 \%$ had skin bleeds/epistaxis. Transiently elevated transaminase levels, which returned to normal after 4 wk were seen in 9 out of 31 cases tested. Ascites was observed in $23 \%$ cases but shock in $5 \%$ only. Increase in the hematocrit $>45 \%$ was observed in none. Mean hospital stay was $3.6 \mathrm{~d}$.

The unique observation during this outbreak of DF was that it was milder and life threatening manifestations of DF like shock, plasma leak and severe hemorrhage were uncommon. Even though laboratory parameters like thrombocytopenia and elevated transaminases were comparable to previous studies, the course of the disease was milder in most of the cases $[3,4]$. Reason being early detection of cases and timely hospitalization, which was facilitated by availability of a quick

P. Sharma $\cdot$ C. M. Kumar $(\bowtie) \cdot$ A. K. Patwari

Department of Pediatrics, Hamdard Institute of Medical Sciences and Research, New Delhi PIN 110062, India

e-mail: cmkumar1@rediffmail.com and early diagnostic test like NS1 antigen detection, augmented by increased awareness among the public and general practitioners during this outbreak. This view is supported by the fact that $12 \%$ cases were admitted with only complaints of fever and myalgia, the sole reason for hospitalization being low platelet counts and/or positive dengue NS1 antigen. Similar observation has been made from Thanjavur [5]. Despite low platelet counts bleeding manifestations were relatively uncommon.

Although the limitation of this study was a small sample size, we conclude that increase in awareness, change in health seeking behavior, early diagnosis and identification of danger signs are positive public health approaches to prevent complications and death following dengue infection.

\section{Conflict of Interest None.}

Role of Funding Source None.

\section{References}

1. Dengue and Severe Dengue. World Health Organisation [Internet] 2012. http://www.who.int/mediacentre/factsheets/fs117/en/. Accessed 7 Jul 2013.

2. Dengue - Guidelines for Diagnosis, Treatment, Prevention and Control. World Health Organisation. [Internet] 2009. http:// whqlibdoc.who.int/publications/2009/9789241547871_eng.pdf. Accessed 3 Jul 2013.

3. Narayanan M, Aravind MA, Thilothammal N, Prema R, Sargunam CS, Ramamurty N. Dengue fever outbreak in Chennai-A study of clinical profile and outcome. Indian Pediatr. 2002;39:1027-33.

4. Ratageri VH, Shepur TA, Wari PK, Chavan SC, Mujahid IB, Yergolkar PN. Profile and outcome of dengue fever cases. Indian J Pediatr. 2005;72:705-6.

5. Krishna MR, Manickavasagam S. The real need of the hour. Indian Pediatr. 2013;50:528-9. 